\title{
Cesarean delivery in a parturient with chronic myeloid leukemia
}

\author{
Rashmi Datta, MD • Ajay Sharma, MD
}

Received: 11 September 2013/Accepted: 9 October 2013/Published online: 17 October 2013

(C) Canadian Anesthesiologists' Society 2013

\section{To the Editor,}

Leukemia rarely occurs during the course of pregnancy, with a reported incidence of 1:75,000-1,000,000 pregnancies. Chronic leukemias account for only $10 \%$ of these cases, with the majority being chronic myeloid leukemia (CML). This disease is characterized by a reciprocal translocation between chromosomes 9 and 22 with the resultant fusion of the breakpoint cluster region (BCR) gene with the Abelson leukemia virus (ABL) gene "Philadelphia chromosome"; $\mathrm{t}(9 ; 22)(\mathrm{q} 34 ; \mathrm{q} 11) .{ }^{1}$ We report a case of newly diagnosed CML in a patient's third trimester. She had been treated for two weeks with hydroxyurea prior to lower uterine segment Cesarean delivery. At that time, the patient's white blood cell count was $194.4 \times 10^{9} \mathrm{~L}^{-1}$ with $5 \%$ myeloblasts in the peripheral blood. General endotracheal anesthesia was administered uneventfully, and a normal healthy baby was delivered uneventfully. Two weeks later, the patient was started on molecular targeted therapy. Both mother and child were doing well after two years of follow-up.

One important consideration for choosing general anesthesia in this case was the potential for blast crisis (BC), a major challenge in the management of leukemia. Blast crisis is defined as the presence of a high blast count, $30 \%$ blasts cells, in the blood/marrow or, in a small proportion of patients, presence of extramedullary blastic

R. Datta, MD ( $\varangle)$

Department of Anesthesiology and Critical Care, Army Hospital (Research \& Referral) Delhi, Delhi, India

e-mail: drrashmidatta@gmail.com

A. Sharma, MD

Department of Haematology, Army Hospital (Research \& Referral) Delhi, Delhi, India infiltrates in the lymph nodes, skin, soft tissues, serosal surfaces, bone, and gastrointestinal and genitourinary tracts. Although rare, leukemic infiltration of meninges and brain, including nerves, can occur even while on therapy. Development of neurological involvement predicts a poorer prognosis with poorer response to treatment and a three-month median survival after the onset. $^{2}$

Chronic myeloid leukemia is routinely diagnosed by an elevated white blood cell count with left shift, frequently with basophilia, and splenomegaly. The presence of BCR$\mathrm{ABL}$ is confirmed with fluorescence in situ hybridization or with polymerase chain reaction (PCR). Bone marrow aspiration and cytogenetic analysis is mandatory for staging the disease as chronic phase (CP), accelerated, or blastic phase (BP). In comparison, all newly diagnosed patients with acute leukemia are routinely subjected to a spinal tap for prognostication. When circulating blast cells are present in the blood in acute lymphocytic leukemias, it is well documented that a traumatic lumbar puncture (TLP) may introduce leukemic blasts from the systemic circulation into the cerebrospinal fluid (CSF) with a resultant two to threefold higher risk of treatment failure. Accordingly, instituting intrathecal therapy early in the course is part of the treatment protocol in patients who have undergone more than one TLP in the presence of peripheral circulating blast cells.,

A diagnostic spinal tap is not part of the routine investigations in CML unless there is a clinical suspicion of involvement of the central nervous system. ${ }^{1,2,4}$ Reports of initiating a BC through a TLP for CML are lacking, and the incidence of diagnostic spinal punctures being performed in CML-CP is also not known. There is a lack of consensus on what constitutes TLP based on CSF rheology because there is no specific threshold for the number of red blood 
cells (RBC) needed to establish the diagnosis of subarachnoid hemorrhage $(\mathrm{SAH})$ and no threshold below which SAH can be excluded. Arbitrary defining cutoffs (e.g., 400, 1,000, and 4,375 RBCs. $\mathrm{mL}^{-1}$ ) have been variously reported. Shah et al. ${ }^{5}$ evaluated $786 \mathrm{CSF}$ samples and reported a $24.3 \%$ incidence of "champagne taps" (defined as zero RBCs in the first and fourth tubes). When they used cutoffs of $400 \mathrm{RBCs}$ and 1,000 RBCs in CSF tube 1, 15.6\% and $10.5 \%$ of samples, respectively, were considered traumatic when compared with the collected sample in tube 4. Lower section Cesarean delivery can be conducted under general anesthesia or under a subarachnoid block; however, a traumatic puncture cannot be ruled out. In view of $5 \%$ blast cells in the peripheral blood, it was decided to administer general anesthesia for this patient as a means to avoid potential introduction of leukemic blasts from the systemic circulation into the CSF.
Conflicts of interest None declared.

\section{References}

1. Fey $M F$, Surbek D. Leukaemia and pregnancy. Recent Results Cancer Res 2008; 178: 97-110.

2. Joseph DE, Emmanuel JD, Dorusinmi MA. Neurological complications of chronic myeloid leukaemia: any cure? Niger $\mathbf{J}$ Clin Pract 2008; 11: 246-9.

3. Gajjar A, Harrison PL, Sandlund JT, et al. Traumatic lumbar puncture at diagnosis adversely affects outcome in childhood acute lymphoblastic leukemia. Blood 2000; 96: 3381-4.

4. Cancela CS, Murao M, Viana MB, de Oliveira BM. Incidence and risk factors for central nervous system relapse in children and adolescents with acute lymphoblastic leukemia. Rev Bras Hematol Hemoter 2012; 34: 436-41.

5. Shah KH, Richard KM, Nicholas S, Edlow JA. Incidence of traumatic lumbar puncture. Acad Emerg Med 2003; 10: 151-4. 